\title{
Particles emitted by a residential wood stove: comparison of various sampling and measuring methods
}

\author{
C. Le Dreff-Lorimier \& M. Dufresne De Viriel \\ CSTB (French Scientific Center for Building Physics), France
}

\begin{abstract}
Although residential biomass combustion is increasingly used, some recent studies present it as a non negligible source of fine particles and gaseous pollutants, which are known to have bad effects on environment and human health. Therefore, characterisation and reduction of these emissions has become a major issue for the industrial, scientific and political communities of this field. But, unlike gaseous pollutants, the evaluation of particles generated by combustion processes may be significantly influenced by sampling and measuring conditions, such as isokinetism or cooling and dilution of the fumes (if any). And, although this impact has been widely studied in case of diesel exhaust particles measurements, very few studies on this subject refer to wood combustion. However, there is currently no unified European norm to measure particles generated by residential biomass combustion appliances and national standards used by some countries (such as Germany or Norway) are based on experimental methods that are widely different from each other, the main discrepancies being in the way fumes are sampled, either in-stack or out-stack. Thus, the objective of this study is to compare the mean mass concentration of particles emitted by a residential wood stove through two different sampling and measuring methods: in-stack gravimetric measurement and out-stack gravimetric measurement (after cooling and diluting fumes in a dilution tunnel). Influence of experimental conditions such as isokinetism, position of sampling probe, type of filter or filter conditioning conditions is studied.
\end{abstract}

Keywords: combustion, biomass, particles, measurements. 


\section{Introduction}

Due to the constant increase in fossil energy costs and the growing attraction for renewable energies, residential heating appliances fired by biomass combustion (insets, wood and pellet stoves, etc...) are rapidly growing. While offering many advantages, these new technologies constitute a non-negligible source of fine particles and gaseous pollutants emissions (CITEPA [1]) that may have bad effects on environment and human health.

But, if gaseous pollutants measurement does not require specific precautions, it is not the same for particles measurement, for which results may be strongly influenced by sampling and measuring conditions (Burtscher [2], Le DreffLorimier [3]). This is especially the reason why a reflexion has recently been initiated by the European Standardisation Comity (CEN) in order to define a common particles measurement method. Indeed, there is actually no standardised European method, so that various techniques can be employed, depending on the laboratories, as is reported in the PrCEN/TS 15883 [4]. Some European countries (Germany, Austria, Norway, Switzerland) have already defined regulatory limit values for particles emission from residential heating appliances, based on national measurement protocols. However, as it is pointed out by Winther [5], Ortega [6] or Johansson et al. [7], large discrepancies may be reported between results obtained from in-stack measurement method (German / Swedish method) and out-stack measurement method (Norwegian method). But although the impact of sampling and measuring conditions has been widely studied in case of diesel exhaust particles measurements, very few studies on this subject refer to wood combustion.

Thus, the objective of this study is to compare the mean mass concentration of particles emitted by a residential wood stove through two different sampling and measuring methods: in-stack gravimetric measurement and out-stack gravimetric measurement (after cooling and diluting fumes in a dilution tunnel). Influence of experimental conditions such as isokinetism, position of sampling probe, type of filter or filter conditioning conditions is studied.

\section{Material and methods}

\subsection{Experimental set-up}

The experimental set-up employed during this study is presented on Figure 1.

As represented on this figure, the tested stove is placed on a scale (KCS600, Mettler Toledo) and connected to an instrumented chimney. This last one is equipped with:

- A CO analyser (ECOM KL, ECOM) for CO continuous measurement respectively in-stack and out-stack (thanks to two butterfly valves);

- An in-stack particles sampling system allowing to collect these particles in view of a gravimetric measurement via a precision scale; it is constituted of heated line and filter holder (containing the particles collection filter), the temperature of which is controlled by a thermocouple placed in surface of the 
filter holder and regulated by a heating wire connected to a power regulator; the sampling line is fitted with a shaped probe in order to limit airflow disturbances at the sampling point, in accordance with NF EN 13284-1 norm [8].

- An out-stack particles sampling system allowing to collect these particles in view of a gravimetric measurement via a precision scale; it is constituted of a dilution hood and an assembly of non-insulated chimneys in which a nonheated sampling line equipped with a filter holder (containing the particles collection filter) is inserted; the sampling line is fitted with a shaped probe in order to limit airflow disturbances at the sampling point.

- A pressure transducer (Model 239, Sestra Systems) for flue draught continuous measurement;

- Two type K thermocouples (Thermo Est) for the measurement of flue gas temperature respectively in-stack and out-stack;

- A vane anemometer (ZS $25 \mathrm{GE}$, Hontzsch) for smoke flow velocity measurement (and thus, to regulate sampling airflow rate for particles sampling devices) respectively in-stack and out-stack.

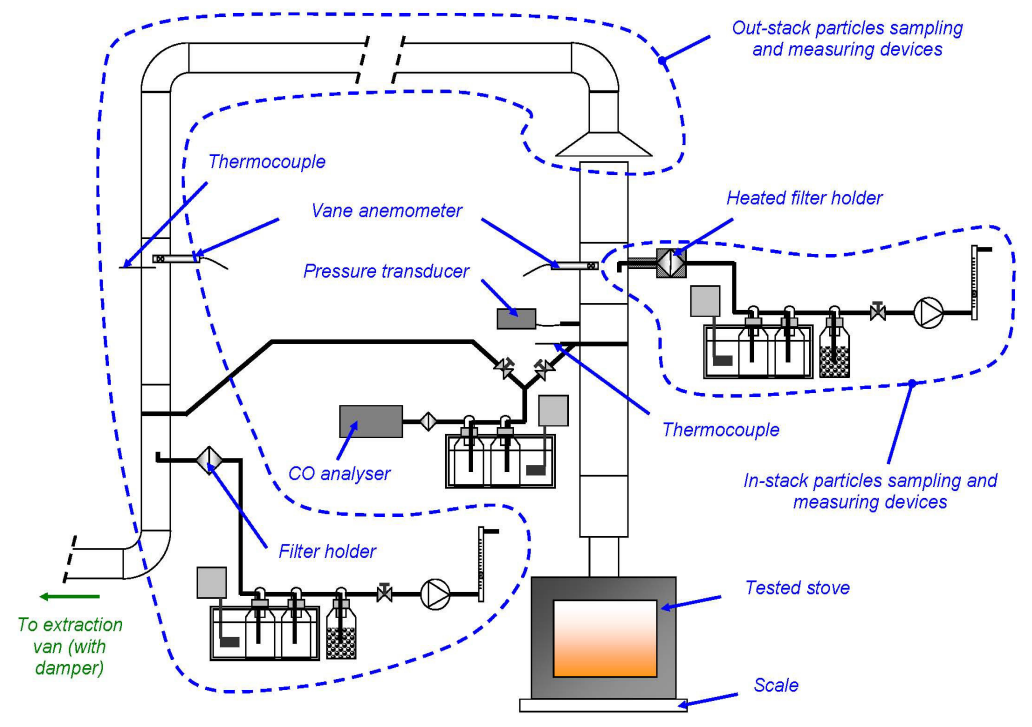

Figure 1: Experimental set-up.

\subsection{Tested stove and fuel}

The tested heating appliance is a wood stove whose characteristics are the following:

- Nominal heat output: $16.2 \mathrm{~kW}$;

- Efficiency: $54.9 \%$. 
The characteristics of the fuel used during these tests are reported in Table 1. For the ignition and pre-tests period, another wood batch (of hornbeam), whose characteristics are not known, is used.

Table 1: $\quad$ Test fuel characteristics.

\begin{tabular}{c|c}
\hline Species & Hornbeam \\
\hline Moisture content & $15.8 \%$ \\
\hline Carbon content (Dry basis) & $42.2 \%$ \\
\hline Ash content (Dry basis) & $1.6 \%$ \\
\hline Hydrogen content (dry basis) & $6.5 \%$ \\
\hline Oxygen content (Dry basis) & $49.5 \%$ \\
\hline Sulfur content (Dry basis) & $0.1 \%$ \\
\hline Net lower calorific value (Dry basis) & $17167 \mathrm{~kJ}^{-\mathrm{kg}^{-1}}$ \\
\hline
\end{tabular}

\subsection{Experimental procedure}

Contrary to what Figure 1 implies, in-stack and out-stack measurements are not performed simultaneously, but successively.

The experimental conditions applied during these tests are reported in Table 2 .

Table 2: $\quad$ Experimental conditions.

\begin{tabular}{c|c}
\hline Pre-tests load & $6.9 \mathrm{~kg}$ \\
\hline Primary air settings & Open at $25 \%$ \\
\hline Secondary air settings & Open at $100 \%$ \\
\hline Test load & $5 \mathrm{~kg}$ \\
\hline Test fuel specificities & 3 wood logs split in two \\
\hline Embers stock & $1.100 \mathrm{~kg}$ \\
\hline Flue draught setting & $-12 \mathrm{~Pa}$ \\
\hline
\end{tabular}

Table 3: $\quad$ Filters characteristics.

\begin{tabular}{c|c|c}
\hline & Glass fiber filter & Quartz fiber filter \\
\hline Manufacturer & PALL & PALL \\
\hline Reference & $\begin{array}{c}\text { Glass Fiber, Type } \\
\text { A/E }\end{array}$ & Pallflex, Tissuquartz \\
\hline Fiber type & Glass fiber & Quartz fiber \\
\hline Binder & Without binder & Without binder \\
\hline Diameter & $47 \mathrm{~mm}$ & $47 \mathrm{~mm}$ \\
\hline $\begin{array}{c}\text { Aerosol retention } \\
\text { (at 0.3 } \boldsymbol{\mu m} \text { DOP) }\end{array}$ & $99.98 \%$ & $99.90 \%$ \\
\hline Maximal temperature of use & $550{ }^{\circ} \mathrm{C}$ & $1093{ }^{\circ} \mathrm{C}$ \\
\hline
\end{tabular}


In order that the operator has time to remove and introduce the filter, an intermediate load of around $1 \mathrm{~kg}$ is fired during these operations (between two test loads).

Two different types of filters are used in this study for particles collection. Their characteristics are reported in Table 3.

\subsection{Methods}

For in-stack measurements, the mean particles mass concentration is calculated thanks to equation (1):

$$
C_{m}=\frac{m_{f i n}-m_{i n i}}{Q_{m} \cdot t_{m}} \cdot \frac{T_{m}}{T_{0}} \cdot \frac{P_{0}}{P_{m}}
$$

where: $C_{m}$ is the mean particles mass concentration (mg. $\left.\mathrm{Nm}^{-3}\right)$;

$m_{\text {ini }}$ is the initial filter mass (mg);

$m_{\text {fin }}$ is the final filter mass (mg);

$Q_{m}$ is the sampling airflow rate at the measurement point $\left(\mathrm{m}^{3} \cdot \mathrm{s}^{-1}\right)$;

$t_{m}$ is the sampling time (s);

$T_{m}$ is the temperature at the measurement point, in ambient condition (K);

$T_{0}$ is the temperature in standardised conditions $(=273.15 \mathrm{~K})$;

$P_{m}$ is the pressure at the measurement point, in ambient condition (= $101300 \mathrm{~Pa}$ );

$P_{0}$ is the pressure in standardised conditions $(=101300 \mathrm{~Pa})$.

For out-stack measurements, the mean particles mass concentration is calculated thanks to equation (2):

$$
C_{m}=\frac{m_{f i n}-m_{i n i}}{Q_{m} \cdot t_{m}} \cdot \frac{T_{m}}{T_{0}} \cdot \frac{P_{0}}{P_{m}} \cdot \frac{1}{\beta} \quad \text { with } \quad \beta=\frac{C O_{f g}}{C O_{d t}}
$$

where: $\beta$ is the dilution factor (-);

$C O_{f g}$ is the mean in-stack $\mathrm{CO}$ content (in the flue gas);

$C O_{d t}$ is the mean out-stack $\mathrm{CO}$ content (in the dilution tunnel).

For all the tests performed (either in-stack or out-stack), the sampling airflow rate to be applied in order to be in isokinetism conditions is determined each 5 minutes, thanks to the flue gas velocity and temperature values (either in-stack or out-stack). This sampling airflow rate is calculated thanks to equation (3):

$$
Q_{m}=v_{p} \cdot S_{p} \cdot \frac{T_{m}}{T_{p}} \cdot \frac{P_{p}}{P_{m}}
$$

where: $Q_{m}$ is the sampling airflow rate at the measurement point (either in-stack or out-stack) $\left(\mathrm{m}^{3} \cdot \mathrm{s}^{-1}\right)$;

$v_{p}$ is the velocity at the measurement point (either in-stack or out-stack) at the entrance of the sampling probe $\left(\mathrm{m} . \mathrm{s}^{-1}\right)$;

$S_{p}$ is the sampling probe cross section $\left(\mathrm{m}^{2}\right)$; 
$T_{p}$ is the temperature at the sampling point (either in-stack or out-stack) $(\mathrm{K})$;

$P_{p}$ is the pressure at the sampling point (either in-stack or out-stack) $(\mathrm{K})$.

In this study, the inner sampling probe diameter is $8 \mathrm{~mm}$, so that $S_{p}=5.03 \times 10^{-5} \mathrm{~m}^{2}$.

\subsection{Tests program}

The objective of this study is to evaluate, for a given heating appliance and in given experimental conditions, the impact of various parameters on particles concentration results. In addition to sampling and measuring method used, the considered parameters are:

- Position of sampling probe and line in the chimney;

- Isokinetism conditions;

- Filter conditioning before and after the tests;

- Sampling line temperature (for in-stack measurements);

- Type of filter.

For each parameter, at least two reproducibility measurements are performed.

The tests programs are reported respectively for in-stack and out-stack measurements in Table 4 and Table 5. In these tables, the sampling probe position is defined from the inner surface of the chimney in which it is inserted.

Table 4: $\quad$ Tests program for in-stack measurements.

\begin{tabular}{|c|c|c|c|c|c|}
\hline & $\begin{array}{c}\text { Airflow } \\
\text { rate }\end{array}$ & $\begin{array}{c}\text { Sampling } \\
\text { probe } \\
\text { position }\end{array}$ & $\begin{array}{c}\text { Filter } \\
\text { holder } \\
\text { tempera- } \\
\text { ture }\end{array}$ & $\begin{array}{c}\text { Filter } \\
\text { condition- } \\
\text { ning }\end{array}$ & $\begin{array}{c}\text { Type of } \\
\text { filter }\end{array}$ \\
\hline $\begin{array}{c}\text { In-Iso-65- } \\
T 160-N F-G\end{array}$ & $Q_{\text {iso }}{ }^{1}$ & $65 \mathrm{~mm}$ & $160^{\circ} \mathrm{C}$ & "NF" 2 & $\begin{array}{l}\text { Glass } \\
\text { fiber }\end{array}$ \\
\hline $\begin{array}{c}\text { In-0.5Iso- } \\
65-T 160- \\
N F-G \\
\end{array}$ & $Q_{\text {iso }} \times 0.5$ & $65 \mathrm{~mm}$ & $160^{\circ} \mathrm{C}$ & "NF" & $\begin{array}{l}\text { Glass } \\
\text { fiber }\end{array}$ \\
\hline $\begin{array}{c}\text { In-1.5Iso- } \\
65-T 160- \\
N F-G\end{array}$ & $Q_{\text {iso }} \times 1.5$ & $65 \mathrm{~mm}$ & $160^{\circ} \mathrm{C}$ & "NF" & $\begin{array}{l}\text { Glass } \\
\text { fiber }\end{array}$ \\
\hline $\begin{array}{l}\text { In-Iso-100- } \\
T 160-N F-G\end{array}$ & $Q_{\text {iso }}$ & $100 \mathrm{~mm}$ & $160^{\circ} \mathrm{C}$ & "NF" & $\begin{array}{l}\text { Glass } \\
\text { fiber }\end{array}$ \\
\hline $\begin{array}{c}\text { In-Iso-65- } \\
T 160-N F-Q\end{array}$ & $Q_{i s o}$ & $65 \mathrm{~mm}$ & $160{ }^{\circ} \mathrm{C}$ & "NF" & $\begin{array}{c}\text { Quartz } \\
\text { fiber }\end{array}$ \\
\hline $\begin{array}{c}\text { In-Iso-65- } \\
T 70-D I N-G\end{array}$ & $Q_{i s o}$ & $65 \mathrm{~mm}$ & $70^{\circ} \mathrm{C}$ & "DIN" 3 & $\begin{array}{l}\text { Glass } \\
\text { fiber }\end{array}$ \\
\hline
\end{tabular}

${ }^{1} Q_{i s o}$ : Sampling airflow rate to be used in order to be in isokinetism conditions.

2 "NF": Before tests: Oven $180{ }^{\circ} \mathrm{C}(\geq 1 \mathrm{~h})+$ Desiccator $(\geq 4 \mathrm{~h})-$ After tests: Oven $160{ }^{\circ} \mathrm{C}$ $(\geq 1 \mathrm{~h})+$ Desiccator $(\geq 4 \mathrm{~h})$.

3 "DIN": Before and after tests: Oven $105^{\circ} \mathrm{C}(\geq 1 \mathrm{~h})+$ Desiccator $(\geq 1 \mathrm{~h})$. 
Table 5: $\quad$ Tests program for out-stack measurements.

\begin{tabular}{c|c|c|c|c}
\hline & $\begin{array}{c}\text { Airflow } \\
\text { rate }\end{array}$ & $\begin{array}{c}\text { Sampling } \\
\text { probe } \\
\text { position }\end{array}$ & $\begin{array}{c}\text { Filter } \\
\text { condition- } \\
\text { ning }\end{array}$ & $\begin{array}{c}\text { Type of } \\
\text { filter }\end{array}$ \\
\hline $\begin{array}{c}\text { Out-Iso-100- } \\
\text { DIN-G }\end{array}$ & $Q_{\text {iso }}{ }^{\prime}$ & $100 \mathrm{~mm}$ & "DIN" & $\begin{array}{c}\text { Glass } \\
\text { fiber }\end{array}$ \\
\hline $\begin{array}{c}\text { Out-D.5Iso- } \\
\text { 100-DIN-G }\end{array}$ & $Q_{\text {iso }} \times 0.5$ & $100 \mathrm{~mm}$ & "DIN" & $\begin{array}{c}\text { Glass } \\
\text { fiber }\end{array}$ \\
\hline $\begin{array}{c}\text { Out-1.4Iso- } \\
\text { I00-DIN-G }\end{array}$ & $Q_{\text {iso }} \times 1.4$ & $100 \mathrm{~mm}$ & "DIN" & $\begin{array}{c}\text { Glass } \\
\text { fiber }\end{array}$ \\
\hline $\begin{array}{c}\text { Out-1.25Iso- } \\
\text { 100-DIN-G }\end{array}$ & $Q_{\text {iso }} \times 1.25$ & $100 \mathrm{~mm}$ & "DIN" & $\begin{array}{c}\text { Glass } \\
\text { fiber }\end{array}$ \\
\hline $\begin{array}{c}\text { Out-Iso-50- } \\
\text { DIN-G }\end{array}$ & $Q_{\text {iso }}$ & $50 \mathrm{~mm}$ & "DIN" & $\begin{array}{c}\text { Glass } \\
\text { fiber }\end{array}$ \\
\hline $\begin{array}{c}\text { Out-Iso-100- } \\
\text { DIN-Q }\end{array}$ & $Q_{i s o}$ & $100 \mathrm{~mm}$ & "DIN" & $\begin{array}{c}\text { Quartz } \\
\text { fiber }\end{array}$ \\
\hline
\end{tabular}

${ }^{1} Q_{\text {iso }}$ : Sampling airflow rate to be used in order to be in isokinetism conditions.

2 "DIN": Before and after tests: Oven $105^{\circ} \mathrm{C}(\geq 1 \mathrm{~h})+$ Desiccator $(\geq 1 \mathrm{~h})$.

\section{Experimental results}

\subsection{In-stack measurements: Impact of studied parameters}

The results obtained during in-stack measurements are reported on Figure 2. Moreover, the mean value for each set of tests is reported in Table 6 .

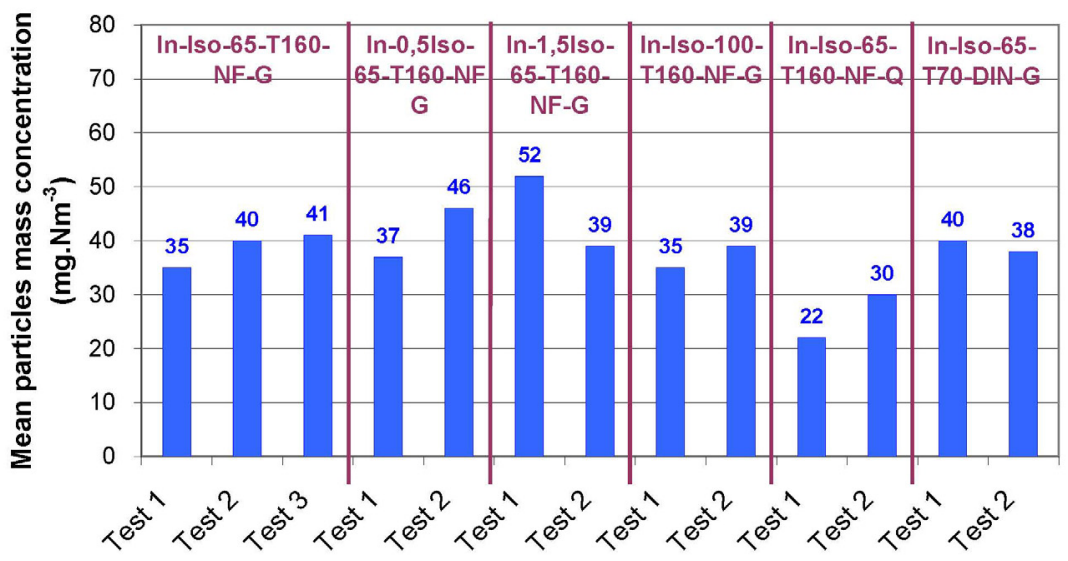

Figure 2: In-stack measurements results. 
Table 6: In-stack measurements mean results.

\begin{tabular}{|c|c|c|c|c|c|c|}
\hline & 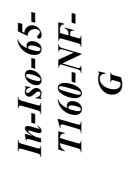 & 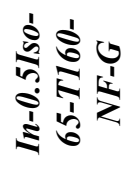 & 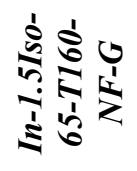 & 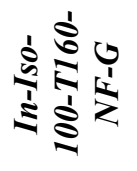 & 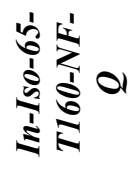 & 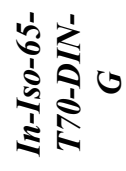 \\
\hline $\begin{array}{c}C_{m} \\
\left(\mathrm{mg}^{\prime} \mathrm{Nm}^{-3}\right)\end{array}$ & 39 & 42 & 46 & 37 & 26 & 39 \\
\hline
\end{tabular}

By taking into account all the results, except those of the tests with change in type of filter ("In-Iso-65-T160-NF-Q"), it appears that the mean value of $C_{m}$ is $40 \mathrm{mg} \cdot \mathrm{Nm}^{-3}$, with a standard deviation of $\pm 3 \mathrm{mg} \cdot \mathrm{Nm}^{-3}$ (that is $8 \%$ related to the mean value).

This mean value seems to be low compared to in-stack values generally reported in previous studies on wood stove (in which sampling and measuring conditions are the same than in this study):

- 89 - 143 mg.m ${ }^{-3}$ according to Kosinski and Saade [9];

- $59-130 \mathrm{mg} \cdot \mathrm{Nm}^{-3}$ at $11 \% \mathrm{O}_{2}$ according to Ehrlich et al. [10].

Nevertheless, as units employed are not exactly the same, it is difficult to evaluate precisely the discrepancies in results (especially concerning Ehrlich et al. results).

By taking into account the minimum and maximum values obtained, it appears that there is a negligible impact of:

- The isokinetism conditions (for the airflow rate range studied);

- The position of sampling probe (for the distances considered);

- The filter holder temperature and the filter conditioning conditions before and after tests (for the conditions considered).

However, by taking into account the minimum and maximum values obtained, the filter characteristics appear to have a non negligible impact on results. Indeed, the mean particles mass concentration for tests performed with a quartz fiber filter is lower (of 35\% in average) than the one for tests performed with a glass fiber filter.

\subsection{Out-stack measurements: Impact of studied parameters}

The results obtained during out-stack measurements are reported on Figure 3. Moreover, the mean value for each set of tests is reported in Table 7.

The mean value of $C_{m}$ for reference tests (that is "Out-Iso-100-DIN-G") is $75 \mathrm{mg} . \mathrm{Nm}^{-3}$, with a standard deviation of $\pm 9 \mathrm{mg}^{-\mathrm{Nm}^{-3}}$ (that is $12 \%$ related to the mean value). This mean value seems to be in accordance with out-stack values reported in the study of Ozil et al. [11] on wood stoves, that is $50-93 \mathrm{mg} . \mathrm{Nm}^{-3}$ at $13 \% \mathrm{O}_{2}$ (for nominal heat output). Nevertheless, as units employed are not exactly the same, it is difficult to make a relevant comparison of these two studies. 


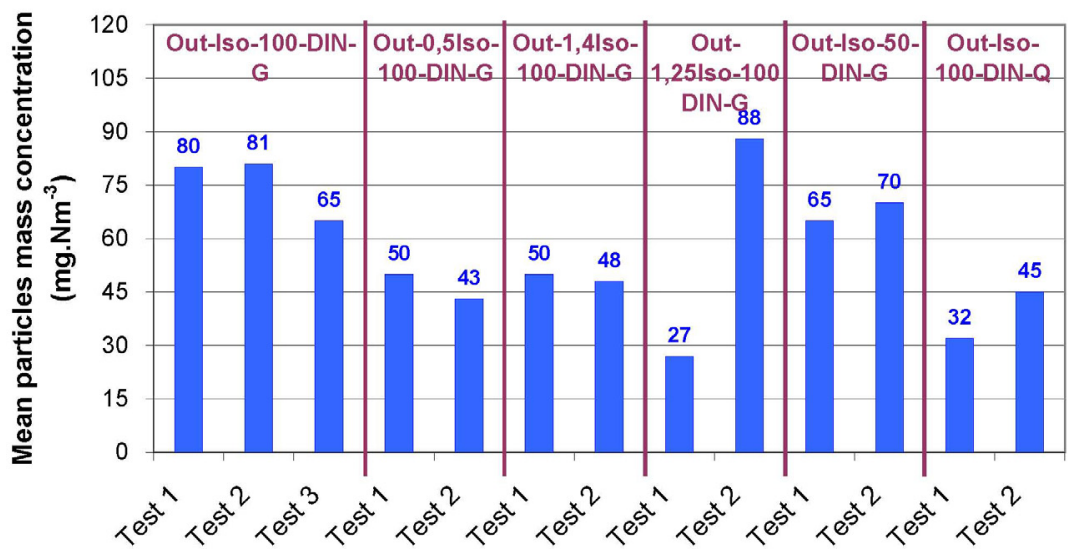

Figure 3: Out-stack measurements results.

Table 7: $\quad$ Out-stack measurements mean results.

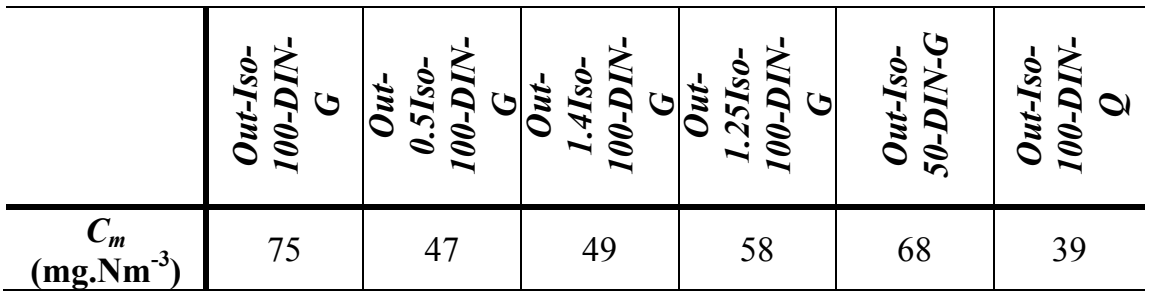

By taking into account the minimum and maximum values obtained, the position of sampling probe appears to have a negligible impact on the results (for the distances considered).

However, by taking into account the minimum and maximum values obtained, it appears that there is a non negligible impact of:

- The isokinetism conditions, even if the discrepancies in results for "Out1.25Iso-100-DIN-G" makes it difficult to conclude. Indeed, "Out-0.5Iso-100DIN-G" and "Out-1.4Iso-100-DIN-G" seems to indicate that the mean particles mass concentration is lower (of around 35\% in average) for tests performed with either a lower or a higher airflow rate than the one corresponding to isokinetism conditions. Some more experiments may be necessary to confirm these tendencies;

- The filter characteristics. Indeed, the mean particles mass concentration for tests performed with a quartz fiber filter, is lower (of $48 \%$ in average) than the one for reference tests performed with a glass fiber filter. 


\subsection{Comparison of in-stack and out-stack results}

The comparison of influent parameters for in-stack and out-stack measurements indicates that the filter characteristics have an important impact on results for both types of sampling methods. Isokinetism conditions, however, only seem to have an impact for out-stack measurements, which have to be confirmed by complementary experiments.

The comparison of "reference" results obtained respectively in-stack and out-stack (that is "Out-Iso-100-DIN-G" and "In-Iso-65-T160-NF-G") reveal that out-stack measurements seem to provide about twice higher values than in-stack measurements, with values of $75 \mathrm{mg} . \mathrm{Nm}^{-3}$ out-stack compared to $39 \mathrm{mg} . \mathrm{Nm}^{-3}$ in-stack. Such results are relevant with those obtained by Ortega [6] and Johansson et al. [7] in studies comparing in-stack and out-stack measurements, in which particles emissions out-stack was even respectively 5 to 14 times higher and 2 to 10 times higher than particles emissions in-stack. This may be explained by the fact that out-stack measurements favour condensation (that is growing of an existing particle due to the agglomeration of gas molecules on its surface) and nucleation (that is formation of new particles from gas molecules) as detailed by Hinds [12] and Lightly et al. [13]. Thus, from out-stack measurements, larger and/or more numerous particles are collected than from in-stack measurements, making these two sampling methods non transposable.

This tendency has now to be confirmed by further experiments on other residential heating appliances.

\section{Conclusions}

From this study, two different sampling methods (either in-stack and out-stack) for particles measurement generated by a wood stove have been studied, such as the influence of some experimental parameters of each method.

By taking into account the minimum and maximum values obtained in-stack, it appears that there is a negligible impact of the isokinetism conditions, the position of sampling probe and the filter holder temperature and the filter conditioning conditions before and after tests (for the conditions considered), whereas the filter characteristics appear to have a non negligible impact on results. Similarly, for out-stack measurements, it appears that there is a negligible impact of the position of sampling probe (for the distances considered), whereas the isokinetism conditions and the filter characteristics appear to have a non negligible impact on results (even if this tendency has to be confirmed by further experiments in case of isokinetism conditions).

Thus, whatever the sampling method, the mean particles mass concentration for tests performed with a quartz fiber filter is lower than the one for tests performed with a glass fiber filter.

Moreover, the comparison of "reference" results obtained respectively in-stack and out-stack reveal that out-stack measurements seem to provide about twice higher values than in-stack measurements, with values of $75 \mathrm{mg}$. $\mathrm{Nm}^{-3}$ outstack compared to $39 \mathrm{mg} . \mathrm{Nm}^{-3}$ in-stack. This tendency has now to be confirmed by further experiments on other residential heating appliances. 


\section{References}

[1] CITEPA, Inventaire des émissions de polluants atmosphériques en France Séries sectorielles et analyses étendues, CITEPA, Réf. CITEPA 622, Février 2007

[2] Burtscher H., Physical characterization of particulate emissions from diesel engines: a review, J. Aerosol Sci., 36, pp. 896-932, 2005

[3] Le Dreff-Lorimier C., Particules issues de la combustion de la biomasse Méthodes de prélèvement et de mesure, CSTB, Rapport CSTB $\mathrm{n}^{\circ} \mathrm{EN}$ CAPE 07-248 C - V0, 2007

[4] PrCEN/TS 15883, Appareils résidentiels à combustibles solides - Méthodes d'essai des émissions, CEN, novembre 2008

[5] Winther K., Comparison of measurement techniques for wood stoves, CEN, CEN/TC295/WG5 N 76/2006, Novembre 2006

[6] Ortega M., Improved combustion in wood stoves, Master of Science in Product Design and Manufacturing, Norwegian University of Science and Technology, August 2008

[7] Johansson L., Gustavsson L., Tullin C., Ryde D., Rönnbäck M., Comparison of particle sampling in chimney and dilution tunnel during residential combustion of wood logs. Proceedings of World Bioenergy 2008, Jonkoping (Sweden), May 2008

[8] NF EN 13284-1, Emissions de sources fixes - Détermination de la faible concentration en masse de poussières - Partie 1: Méthode gravimétrique manuelle, AFNOR / CEN, Mai 2002

[9] Kozinski J.A., Saade R., Effect of biomass burning on the formation of soot particles and heavy hydrocarbons. An experimental study, Fuel, 77(4), pp. 225-237, 1998

[10] Ehrlich C., Noll G., Kalkoff W.-D., Baumbach G., Dreiseidler A., $\mathrm{PM}_{10}$, $\mathrm{PM}_{2.5}$ and $\mathrm{PM}_{1.0}-$ Emissions from Industrial Plants. Results from Measurement Programmes in Germany, Atmospheric Environment, 41,pp. 6236-6254, 2007

[11] Ozil F., Haas F., Trouve G., Size distributions and emission factors of $\mathrm{PM}_{1}$ and $\mathrm{PM}_{2.5}$ during wood combustion in domestic fireplaces. Proceedings of DustConf2007, Maastricht (Netherlands), April 2007

[12] Hinds W.C., Aerosol Technology - Properties, Behavior, and Measurement of airborne particles - $2 d$ Edition, John Wiley \& Sons: USA, 1999

[13] Lightly J.S., Veranth J.M., Sarofilm A.F., Combustion Aerosols: Factors Governing Their Size and Composition and Implications to Human Health, J. Air \& Waste Manage. Assoc., 50, pp. 1565-1618, 2000 